\title{
O local do global: as contribuições sociológicas de Roland Robertson acerca da globalização ${ }^{1}$
}

\section{The local of the globall: Sociological contributions of Roland Robertson about globalization}

Pedro Wilson Oliveira da Costa Junior ${ }^{2}$

\section{Resumo}

Empregado para explicar variados fenômenos, o termo globalização relaciona-se às questões políticas entre estados-nação, bem como, às novas configurações das interações sociais em escala global. Tais discussões conectam variados elementos, como modernidade e pós-modernidade, desenvolvimento e subdesenvolvimento, ocidentalização, identidade, entre outros. Neste breve ensaio, aborda-se a contribuição teórica de Roland Robertson na sociologia contemporânea acerca da temática, com destaque para a ideia de "glocalização" que refuta perspectivas homogeneizantes da cultura, apontando mediações da globalização aos distintos contextos sociais.

\footnotetext{
1 Este trabalho foi elaborado inicialmente para a disciplina Teorias Sociológicas Contemporâneas, ministrada pelo Prof. ${ }^{\circ}$ Dr. Carlos Benedito Martins, no curso de Doutorado em Sociologia da Universidade de Brasília, em 2013

2 Professor do Instituto Federal de Brasília - IFB. Doutorando em Sociologia pela Universidade de Brasília (UnB) e bolsista do CNPq. Mestre em Sociologia pela Universidade Federal do Ceará (2010) e graduado em Ciências Sociais pela Universidade Federal do Ceará (2008). Email: pedrowilsonsg@terra.com.br
}

Revista Cadernos de Estudos Sociais e Políticos, v. 5, n. 9, jan-junho 2016 
Palavras-chave: globalização, modernidade, sociologia.

\begin{abstract}
Used to explain various phenomena, the term globalization is related to political issues between nation-states, as well as a new configuration of social interactions on a global scale. Such discussions connect various elements such as modernity and post-modernity, development and underdevelopment, Westernization, identity, among others. This brief essay discusses the theoretical contribution of Roland Robertson in contemporary sociology on the theme, highlighting the idea of "glocalization," which refutes homogenizing perspectives of culture, pointing mediations of globalization to different social contexts.
\end{abstract}

Keywords: globalization, modernity, sociology. 


\section{Introdução}

Neste trabalho são apresentados, em linhas gerais, os aspectos mais relevantes da obra de Roland Robertson (1999; 2003) sobre a "globalização" e o debate realizado com outras perspectivas teóricas. Nessa obra - que figura dentre as contribuições mais relevantes sobre o tema - o sociólogo britânico/americano analisa o movimento que dota a população mundial de maior interdependência, envolvendo desde relações macropolíticas entre estados-nações até a reconfiguração das interações sociais face a essa dinâmica e aponta para o fortalecimento de uma "consciência global" ao longo do século XX. De acordo com o autor, desde o final da década de 1970, a sociologia tem redefinido seu alcance e seu campo de estudo em relação aos processos globais.

Alinhada à conjectura de uma "sociedade pós-industrial" emergente, a ideia de globalização foi introduzida em diversas áreas do conhecimento. Cumpre destacar sua interação com diferentes categorias, tais como modernidade, pós-modernidade, desenvolvimento, subdesenvolvimento, ocidentalização, identidade, cultura local, ou mesmo a antiga problemática da Gemeinschaft [comunidade]/ Gesellschaft [sociedade] (ROBERTSON, 1999). No geral, os apologistas da "globalização" advogam que, nas últimas décadas, teria se sucedido uma alteração qualitativa na história do mundo e que o instrumental teórico disponível não daria conta de interpretar tal dinâmica. Teóricos contemporâneos chegam a acusar a sociologia de ser prisioneira do estadonação; e que na era global, determinadas perspectivas sociológicas estariam sob o risco de se tornarem "peças de museu" devido ao nacionalismo metodológico que as alicerça (BECK, 2004; KHONDKER, 2004).

O conceito de globalização não tivera reconhecimento significativo no 
circuito acadêmico até meados da década de 1980. Críticos reticentes à ideia argumentavam que o movimento de integração mundial, constituído pelo comércio global, pela difusão de culturas e pela interação de indivíduos e grupos de regiões distantes ocorria a séculos, constatando, assim, que o fenômeno firmado pelo conceito seria pouco inovador. E o que consistiria efetivamente num diferencial histórico do último período seria a emergência de uma economia cada vez mais "mundializada" sob a hegemonia do capital financeiro (CHESNAIS, 1996).

Robertson (1999) rejeita qualquer ideia que assimile a sociedade mundial estabelecida enquanto produto de um único e exclusivo processo, tal como "imperialismo" ou "ocidentalização". Assinala que a globalização inaugurada no século XV - seria anterior ao advento da modernidade e que a difusão desta, ainda que diversificadamente, teria ocorrido justamente em função da interdependência global. E não obstante o fenômeno possuir alguns séculos de existência, o cerne do debate da globalização só teria ganhado relevância num período relativamente recente. Robertson (1999) rebate, assim, concepções teóricas que dão primazia à dimensão econômica desse processo e que também sugerem uma uniformização global das culturas, cuja principal característica seria o predomínio de determinadas regiões perante outras. Além de fixar o caráter multifacetado da globalização em detrimento de um viés economicista, o autor sustenta que as realidades locais estariam, na verdade, sendo preservadas ou mesmo fortalecidas nessa dinâmica, expresso na proposição de "glocalização", ideia inspirada na cultura japonesa.

\section{Globalização e Teoria Social}


Os sociólogos clássicos teriam se deparado com a simultaneidade dos processos de nacionalização e de globalização, e, de acordo com Robertson (1999), este dilema marcaria o nascimento da sociologia moderna. Na obra de Auguste Comte já estava contido apontamentos de um universalismo, sobretudo em proposições como a de uma "religião da humanidade". Em Durkheim seria notável o esforço de analisar o relacionamento entre particularismo e universalismo, conforme ilustra Robertson com a proposição do sociólogo francês de que a heterogeneidade dos indivíduos seria uma das predisposições das sociedades modernas. Contudo, entre os clássicos, teria sido Weber o que mais se destacara na questão da modernidade. De acordo com o sociólogo alemão, o mundo seria basicamente uma arena de luta entre nações, e tal luta ocorrendo no interior de uma economia mundial crescentemente interligada. Entretanto, Robertson assinala que Weber teria uma "imagem parcial da compressão do mundo"; em outros termos, um olhar "unidimensional" do que agora é denominado de globalização (ROBERTSON, 1999: 44).

Robertson (1999) confere criticamente a classificação que Martin Albrow (1990 apud ROBERTSON, 1999: 40) fizera da história da sociologia em cinco estágios: universalismo, sociologias nacionais, internacionalismo, indigenização e globalização. O estágio do universalismo, de estreitos vínculos com o iluminismo, apontava para o anseio dos pensadores (SaintSimon, Comte e Marx seriam seus principais expoentes) em garantirem uma ciência alicerçada em princípios universais, atemporais e leis verificáveis. $\mathrm{O}$ estágio das sociologias nacionais, que não abandonara totalmente as aspirações universalistas, esteve marcado pela profissionalização da disciplina nas academias do mundo ocidental e pelo confinamento da produção sociológica em fronteiras nacionais. Todavia, Robertson julga 
exageradas as diferenças estabelecidas por Albrow (1990) entre o estágio universalista e o segundo estágio.

O período após a Segunda Guerra Mundial marcou o colapso das sociologias nacionais e inaugurou o estágio que Albrow (ibidem) denominara “internacionalismo", determinado pelas teses da modernização e tendo em Parsons o seu principal teórico. Robertson critica a ausência de uma zona intermediária entre as sociologias nacionais e a fase do internacionalismo cujo colapso teria sido mais um exagero de Albrow - além do pouco destaque à problemática do relativismo, expressa entre as décadas de 1920 e 30, sobretudo nas obras de Max Scheler e Karl Mannheim. O estágio da "indigenização" seria o momento em que alguns expoentes de sociologias nacionais, sobretudo no chamado Terceiro Mundo, buscariam introduzir suas produções em uma “sociologia mundial". Robertson (1999) assevera que Albrow não fizera uma convincente distinção deste estágio no que diz respeito às sociologias nacionais. Ele afirma que existem duas características prevalecentes no avanço da "indigenização" do Terceiro Mundo durante a década de 1970: oposição aos métodos ocidentais e a ênfase na tradição cultural nacional, e, não obstante, a forte tendência em se apoiar em modelos marxistas (ALBROW, 1990 apud ROBERTSON, 1999: 40).

Finalmente, a "globalização da sociologia" seria produto da interação entre nacionalismo e internacionalismo, bem como das fases precedentes. Apontando para a emergência de um discurso universal acerca dos processos globais, partindo de variados interlocutores de distintas regiões e culturas, os sociólogos necessitariam enfrentar a diversidade e interpretar a sociedade global como um novo patamar da realidade social (ibidem). Robertson (2003) aponta a existência de uma "mitologia da globalização" na sociologia, assentada no suposto triunfo de forças culturalmente homogeneizadoras 
perante as demais. Além disso, haveria uma tendência a se pensar a globalização de maneira "casual", cabendo seu interesse apenas a sociólogos interessados em fenômenos macrossociais e conferindo assim um processo teoricamente "desorientador" e demasiadamente negligente com as circunstâncias globais. "Boa parte da teoria social tradicional favorece o abstrato e o local, numa perspectiva global simplista, em prejuízo dos contornos globais e civilizacionais e das bases da própria teoria ocidental." (ROBERSTON, 1999: 80).

Robertson advoga a existência de uma "autonomia geral e de uma 'lógica' em relação ao processo de globalização - que atua com relativa independência em relação aos processos estritamente sociais e a outros processos culturais convencionalmente estudados" (ROBERTSON, 1999: 90). O exercício de interpretação do mundo contemporâneo, conforme o autor explica, implicaria compreender os fundamentos da disciplinaridade e da interdisciplinaridade contemporâneas com vistas a compreender a estruturação do "mundo como um todo". Desse modo, a teoria social "deveria ser retomada e expandida a ponto de se ocupar com o 'mundo' e fazer dele uma hermenêutica central e de tal forma que levasse a pesquisa empírica e histórico-comparativa na mesma direção.” (ROBERTSON, 1999: 80). Segundo Robertson, ao refletirmos acerca da história global como algo que se define no curso de um longo período e na pluralidade de distintas civilizações, com os vários níveis de separação entre elas, a tarefa central da sociologia consistiria então em discernir as conformações que fizeram o mundo transitar de um ser "em si" para a perspectiva de um "ser para si" (ROBERTSON, 1999: 84).

\section{Consciência global e culturas locais}


Para Robertson (1999), a globalização refere-se concomitantemente à "compressão do mundo" e à intensificação do que ele denomina de "consciência da totalidade global". Para o autor, o século XX presenciou uma "revolução da consciência global", reforçando a ideia de "entrelaçamento" entre diferentes partes do mundo. Os eventos que sacudiram a humanidade desde as guerras mundiais, a modernização do chamado "Terceiro Mundo" engendrando uma nova "estratificação internacional" -, a edificação de instituições internacionais e transnacionais e a consolidação da economia global, foram decisivos no que Robertson assinala como "duplo processo de globalização 'objetiva' e de globalização 'subjetiva"” (ROBERTSON, 1999: 25).

A noção de uma "compressão do mundo" já estaria presente na obra de McLuhan (1998 [1964]), residindo nas categorias de "simultaneidade partilhada" e de "aldeia global", no bojo das reflexões acerca da experiência da mídia, principalmente televisiva. "Existe pouca dúvida de que McLuhan, simultaneamente, refletiu e deu forma às tendências da mídia, tanto que agora estamos testemunhando as tentativas da própria mídia em consolidar a ideia de comunidade global." (ROBERTSON, 1999: 24). Tal processo, todavia, ocorreria progressivamente desde muitos séculos, e parte significativa da história mundial poderia ser considerada como "uma sequência da 'miniglobalização', no sentido em que, por exemplo, a formação histórica do império envolveu a unificação dos territórios e entidades sociais previamente confiscados" (ROBERTSON, 1999: 83).

A globalização estaria dividida em cinco fases para Robertson. A primeira, "embrionária", começa no século XV indo até a metade do século XVIII, marcada pelo declínio do sistema "transnacional" medieval e pela ascensão de comunidades nacionais; além da acentuação das ideias de indivíduo e de 
humanidade. Na "fase incipiente", que vai até a década de 1870, consolidamse as ideias de estado unitário homogêneo, relações internacionais formalizadas, cidadania, e um conceito de gênero humano mais concreto. A "fase da decolagem", desde a década de 1870 até a metade da década de 1920, refere-se ao período de "tendências globalizantes" manifestas na emergência de uma "sociedade internacional", com o registro das primeiras problematizações acerca da "modernidade". A "fase da luta pela hegemonia", entre a década de 1920 e a primeira metade da década de 1960, foi caracterizada por disputas e guerras devido à fragilidade dos termos estabelecidos ao final do período de decolagem. Por fim, a "fase da incerteza", iniciada na década de 1960 e responsável pela crise no início da década de 1990, é marcada pelo amplo desenvolvimento dos meios de comunicação, pela intensificação da consciência global e dos valores "pósmaterialistas" (ROBERTSON, 1999: 88-89).

O período de "grande incerteza global" que adentramos teria se propagado como algo globalmente instituído. Robertson (1999) assinala que o que fora repetidamente chamado de política mundial durante o século XX dependia, grosso modo, "das interpretações da resposta ou das respostas à modernidade, cujos aspectos foram política e internacionalmente debatidos como o padrão de 'civilização' durante o final do século XIX e início do século XX” (ROBERTSON, 1999: 79), equivalendo ao processo de admissão de sociedades não europeias à "sociedade eurocêntrica internacional". Tal problemática, assevera, corresponderia a uma dinâmica de unificação, contudo sem integração do mundo como um todo: "Sustento que a chamada globalização, a despeito dos conceitos divergentes sobre o tema, pode ser melhor entendida como indicativo do problema da forma como o mundo se torna 'unido', mas não integrado, de forma funcional simplista." 
(ROBERTSON, 1999: 79).

Uma parcela crescente de movimentos sociais, organizações políticas, grupos de interesse tem suas expectativas com a globalização, de acordo com Robertson (1999), da mesma forma que alguns "analistas"; e estes últimos não poderiam ser apartados dos "participantes", pois também possuiriam interesses difusos acerca do tema. Robertson (1999: 27-28) aponta a existência de um debate entre "convergência" e "divergência" na globalização. Em suma, os defensores da convergência indicavam que praticamente todas as sociedades se moviam, com celeridades distintas, na mesma direção. Já os partidários da corrente divergente destacavam a existência de diferenciadas formas de ingresso à "modernidade". A configuração desse debate entre convergência e divergência se dirigia para a cristalização de uma ideia implícita: a homogeneização de um "sistema mundial".

No início da década de 1970, as teorias de modernização que avaliavam as sociedades exclusivamente de forma comparativa, tendo como modelos de referência as sociedades ocidentais, sofreram um forte desafio. Tratava-se da “Teoria dos Sistemas Mundiais", de Immanuel Wallerstein, que sustentava a existência de um padrão sistemático de relações entre sociedades. De acordo com a perspectiva wallersteiniana, o capitalismo se fortaleceria consoante às sociedades, tomando parte no desenvolvimento do sistema mundial como decorrência das suas posições no interior da sistêmica divisão mundial do trabalho (WALLERSTEIN, 2005). Robertson (1999) avalia como "unilateral" a teoria de Wallerstein, sobretudo pela primazia do viés econômico em detrimento das dinâmicas culturais ao abreviar a leitura da expansão do "mundo" a um decurso da expansão do capitalismo. "As relações políticas e militares fluem ao longo das linhas indicadas por aquelas relações 
econômicas básicas enquanto que a cultura, incluindo a religião, é muito epifenomenal." (ROBERTSON, 1999: 32). Robertson assinala seu conceito de globalização como mais "abrangente, aberto e fluido do que o conceito de sistema mundial de Wallerstein" (ibidem), e que abarca a tentativa de expor os aspectos mais significativos do mundo como um todo. Não obstante as perspectivas de Wallerstein e de Robertson possuírem elementos importantes em comum, "a análise da globalização e a análise dos sistemas mundiais são perspectivas rivais" (ibidem).

Outro teórico que travou debate com a Teoria do Sistema-Mundo foi William Robinson (2011). Para este autor a globalização constitui qualitativamente uma nova época na evolução contínua do capitalismo mundial, marcada por uma série de mudanças fundamentais no sistema capitalista, envolvendo dimensões que não podem ser explicadas pelo paradigma dos sistemas mundiais. $\mathrm{O}$ autor reserva o termo globalização para se referir às mudanças ocorridas nas últimas décadas, tais como a transição de circuitos nacionais de acumulação para um mercado global integrado, e o surgimento de um Estado transnacional, composto de uma frouxa rede formada por instituições políticas e econômicas supranacionais. Robinson (2011: 740) argumenta que existe uma alteração entre espaço e acumulação que Wallerstein ignoraria ${ }^{3}$. A

3 Em artigo réplica, Wallerstein (2012) rebate as críticas de Robinson (2011) de que sua teoria seria "estadocêntrica", pois contraria o próprio nome da perspectiva. A realidade social ocorreria no interior de um "sistema-mundo" e não dentro de estados-nações. Ademais, Robinson teria feito uma interpretação equivocada da ideia de "centro-periferia", pois não se referiria a uma relação entre estados, mas uma relação em que a diferença fundamental é o grau de monopolização do processo produtivo que resulta de diferentes políticas nacionais. Por fim, a visão de Robinson acerca da "globalização" como uma nova etapa do capitalismo, na qual as instituições financeiras seriam as principais agentes na acumulação capitalista, é encarada por Wallerstein como oriunda de uma crise estrutural no equilíbrio do atual sistema-mundo que desembocará nas próximas décadas num novo sistema-mundo, ainda que se desconheça suas 
atual configuração do espaço seria menos territorial e o Estado-nação seria apenas mais uma entre outras formas históricas possíveis de configurar o espaço social. Robinson (2011) também questiona a ideia de dominação de países/culturas por outros, conforme apregoaria a Teoria do Sistema-Mundo. Para o autor, a acelerada integração dos povos em estruturas sociais globais provocadas pela globalização implica numa transmissão cultural e no compartilhamento de símbolos, mediante estratégias adaptativas ${ }^{4}$.

Robertson (1999) também não concorda que o mundo possa ser resumido por suas características sistêmicas, e afirma que a teoria dos sistemas mundiais continua "perseguindo um futuro mundo socialista em que homens e mulheres possam fazer a história voluntariamente" (ROBERTSON, 1999: 30). Embora evidencie as divergências com a teoria de Immanuel Wallerstein, sobretudo em função do "economismo", Robertson atesta a seriedade da tese de Wallerstein, principalmente por sua perspectiva teórica que, com vistas ao global, se constituiu num contraponto à sociologia convencional que, durante o século XX, fora mantida "em cativeiro pela institucionalização [...] da ideia do sequestro da sociedade nacional culturalmente coerente, durante a fase principal da sociologia "clássica"” (ROBERTSON, 1999: 76).

Também visando contrariar determinadas concepções teóricas que

diferenças qualitativas com o atual (WALLERSTEIN, 2012).

4 "The culture and ideology of global capitalism - consumerism, individualism and competition - are less 'western' or 'core' than global capitalist patterns and are imposed as much from within by local contingents of the transnational capitalist class and transnationally oriented elites (see later) as from without by agents from other regions. Conversely, cultural symbols are created and appropriated by the oppressed and culture can and does subvert as much as it dominates. It is in this resistance that groups draw on historical geocultures and adapt them to entirely new circumstances, including rescripting and even mythologizing them" (ROBINSON, 2011: 733). 
propunham que o "programa cultural da modernidade", tal qual erigido na Europa, acabaria por dominar todas as sociedades modernas e as em vias de modernização, a perspectiva das "modernidades múltiplas" (EISENSTADT, 2001) contesta as teorias clássicas da modernização que interpretavam o mundo moderno através do olhar do Ocidente, ressaltando que "os padrões ocidentais de modernidade não constituem as únicas modernidades 'autênticas', apesar de gozarem de precedência histórica e de continuarem a ser um ponto de referência básico para os restantes" (EINSENSTADT, 2001: 157). O processo de globalização contemporâneo revelaria uma "contínua reinterpretação do programa cultural da modernidade", marcado por "tentativas por parte de diversos grupos e movimentos de se apropriarem e redefinirem o discurso da modernidade nos seus próprios termos" (ibidem). O que não implicaria necessariamente num "choque de civilizações" ou num hipotético confronto entre o Ocidente secular e sociedades que rejeitam a ocidentalização.

Com efeito, Robertson (2003) também indica uma interação entre homogeneização, que difunde padrões globais, e a heterogeneidade, que acolhe a diversidade cultural do local. No geral, haveria uma tendência no debate da globalização em compreendê-la enquanto processo de superação do "local". "Tal interpretación descuida dos cosas. Primero, que la extensión de lo que se tiene por local se ha construido en gran parte sobre una base que va mas allá de lo local (translocal) o que lo supera (superlocal)." (ROBERTSON, 2003: 263). Para o sociólogo, grande parte dos fenômenos considerados como expressão do "local", existe em função do movimento da globalização, feita a partir de cima ou de fora, acatando as distinções culturais do lugar (ROBERTSON, 2003). Mesmo as reivindicações de etnia e nacionalidade encontram lugar nos termos gerais de identidade $\mathrm{e}$ 
particularidade.

El argumento que vertebra toda esta discusión se centra, pues, en el propósito de transcender el debate sobre "homogeneización global" frente a "heterogeneización". No se trata de escoger entre "homogeneización o heterogeneización", sino de los modos en que ambas tendencias han llegado a constituir estilos de vida a lo largo de buena parte del último tramo del siglo $\mathrm{XX}$. Y en tal perspectiva el problema pasa a ser perfilar la manera de cómo ambas tendencias se implican mutuamente. De hecho, esto constituye un problema empírico mayor de lo que pudiera pensarse en principio. En diversas áreas de la vida contemporánea [...] se están dando sucesivos y calculados intentos de combinar homogeneidad con heterogeneidad y universalismo con particularismo. (ROBERTSON, 2003: 265).

Entretanto, cumpre assinalar, conforme a socióloga Saskia Sassen (2010), que a complexidade da atual reprodução do capitalismo global incide justamente em demandas materiais e locais dentro de uma "geografia estratégica" 5 . Seria através das "cidades globais" - sediadas em espaços nacionais específicos - e, sobretudo, mediante a rede que conecta estes locais, que a economia global seria gerida e reproduzida. Desse modo, vale problematizar a materialidade das configurações dos "locais" e as hierarquias estabelecidas entre eles, além das disparidades internas resultantes da dinâmica de integração global, aspectos aparentemente preteridos em Robertson. Robertson (2003) reconhece que a “cultura global” está carregada de determinadas mensagens culturais, especialmente estadunidenses, mas

5 "Esses locais geram geografias específicas da globalização e enfatizam o nível em que elas não abrangem o mundo todo. Além disso, são geografias em mutação que foram transformadas nos últimos séculos e nas últimas décadas." (SASSEN, 2010: 92). 
ressalta que os produtos são absorvidos e interpretados de maneiras distintas pelas culturas locais. "Lo global no se contrapone en sí mismo ni por sí mismo a lo local. Más bien aquello a lo que nos solemos referir como local está esencialmente incluido dentro de lo global." (ROBERTSON, 2003: 276). Além disso, justifica o autor, é crescente a tendência dos produtores em conceber seus produtos para um mercado global diversificado.

Antes de se aventurar nas áreas de sociologia comparativa e estudos da modernização, Roland Robertson realizou suas primeiras investigações na área da sociologia da religião. Seu conhecimento acerca da sociedade japonesa possibilitou descobrir a ideia de "glocalização" (ROBERTSON, 2003), um termo que especialistas em marketing estavam usando para definir a adequação dos produtos de origem japonesa para o gosto e interesses locais ${ }^{6}$.

[...] la glocalización puede ser -y así ocurre de hecho- usada estratégicamente, como ocurre con las estrategias de glocalización empleadas por las empresas contemporáneas de televisión a la búsqueda de mercados globales (MTV Y CNN entre otras). Al argumentar que el concepto al uso de globalización implica lo que estaría mejor descrito como glocalización, no dejo de reconocer en absoluto que existen muy diferentes modos de glocalización en la práctica. Y aunque gran parte de lo aquí ¡le expuesto depende del concepto japonés de glocalización, de hecho he generalizado el concepto de manera que, en principio, abarque al mundo entero. En esta última perspectiva, la noción japonesa de glocalización

6 O termo "glocal" e "glocalização" foram inspirados pela palavra japonesa "dochakuka" ("aquele que vive em sua própria terra"), referente ao princípio agrícola de adaptar as técnicas de para as condições locais, mas desde a década de 1980 tem sido adotada dentro do jargão empresarial japonês para definir uma visão global adotada para as condições locais (KHONDKER, 2004). 
aparece como una versión particular de un mismo fenómeno general.(ROBERTSON, 2003: 282).

Khondker (2004: 6) assinala outra visão acerca dos processos globais assentada na ideia de "hibridização" que propunha que a extensão cultural pode ser vista como um intercâmbio, difusão etc., em que o cruzamento, empréstimos e adaptação às necessidades locais seriam muito comuns. Não obstante a ideia de "glocalização" ter ressonância em aspectos daquela categoria, significativas diferenças conceituais estariam colocadas; Robertson propõe o conceito enquanto contraposição à ideia de "McDonaldização" do mundo (RITZER, 2000), noção que sugeriria um mundo homogeneizado, com a "cultura global” suplantando as culturais locais. A "glocalização" seria então uma globalização que institui fronteiras, pois esta necessita se ajustar às realidades locais, ao contrário de simplesmente aniquilá-las ou desprezálas (ROBERTSON, 2003). Com efeito, ao ocasionar uma defesa a si própria - criando um movimento global de resistência - a globalização, na visão de Robertson, contribuiria para a preservação de realidades locais.

\section{Considerações finais}

Distante de pretender apresentar aspectos conclusivos acerca do debate da globalização, o que é patente entre distintas leituras da contemporaneidade global é a insuficiência do instrumental sociológico solitariamente dar conta de interpretar processos tão complexos e difusos. Com vistas a se debruçar sobre a conectividade cultural e econômica em âmbito global, torna-se imperativo uma leitura cada vez mais abrangente das sociedades e de suas instituições. Daí ser imprescindível a adoção de uma perspectiva 
interdisciplinar no exame do "campo global", conforme apregoado por Robertson (1999).

A noção de "glocalização" permite introduzir na globalização uma realidade multidimensional e, ademais, a junção entre global e local impede que o termo "local" defina exclusivamente certa ideia de identidade, cômoda diante do caos da modernidade. Não obstante o esforço teórico do sociólogo britânico em demonstrar que a globalização não estaria resumida à sua dimensão econômica - e tendo o "local" como agente definidor de sentido para o processo macrossocial -, parece praticamente inescapável desassociar tal processo do novo salto que as instituições econômicas globais possuíram nas últimas décadas, tais como apontados, distintamente, por Wallerstein (2005; 2012) e Robinson (2010); bem como perceber assimetrias constituintes dessa interação entre o "local" e o "global".

Para compreender a história global, no entendimento de Robertson, é indispensável o exame da "pluralidade de distintas civilizações". No entanto, talvez a recusa de leituras "economicistas" explique a pouca atenção dada pelo autor ao estudo das dessemelhanças e hierarquias entre os "locais" e no interior destes, reservando-se a consentir que “o mundo se torna 'unido', mas não integrado" (ROBERTSON, 1999: 79). Vale questionar, considerando a confluência de padrões culturais distintos, quais parâmetros estão disponíveis para mensurar o equilíbrio ou o predomínio de certos valores culturais sobre outros, bem como qual seria a possibilidade de conferir uma ideia de modernidade que não seja orientada por certos vieses, seja o econômico ou o "Ocidental". Estes questionamentos também são cabíveis a perspectiva das "modernidades múltiplas", de Eisenstadt (2001). Por fim, cumpre frisar que as divergências teóricas são próprias da elaboração do conhecimento sociológico e que a disciplina possui posição privilegiada para problematizar 
diversos fenômenos relacionados à globalização, assim como outras disciplinas, resguardando a importância da autonomia de cada campo para explorar a partir de seus próprios quadros conceituais. Desse modo, caberá um esforço de síntese para análises vindouras. 


\section{REFERÊNCIAS BIBLIOGRÁFICAS}

ALBROW, Martin. "Globalization, knowledge and society". In: ALBROW, Martin; KING, Elizabeth (eds.). Globalization, knowledge and society. Londres: Sage Publications, 1990, pp. 3-13.

BECK, Ulrich. "How not to become a museum piece". The British Journal of Sociology, vol. 56, $\mathrm{n}^{\circ}$ 3, 2005, pp:335-343.

CHESNAIS, François. A mundialização do capital. São Paulo: Xamã, 1996.

EISENSTADT, Shmuel N. "Modernidades Múltiplas". Sociologia, Problemas e Práticas, n 35, 2001, pp. 139-163,

KAYA, Ibrahim. "Modernity, openness, interpretation: a perspective on multiple modernities". Social Science Information, vol. 1, $\mathrm{n}^{\circ}$ 43, 2004, pp. 35-57.

KHONDKER, Habibul Haque. "Glocalization as globalization: evolution of a sociological concept". Bangladesh e-Journal of Sociology, vol. 1, $\mathrm{n}^{\mathrm{o}}$ 2, 2004, pp. 1-9.

McLUHAN, Marshall. Os meios de comunicação como extensão do homem. São Paulo: Cultrix, 1998.

RITZER, George. The McDonaldization of society. Thousand Oaks, California: Pine Forge, 2000.

ROBERTSON, Roland. "Glocalización: tiempo-espacio y homogeneidad heterogeneidad”. In: MODEDERO, Juan Carlos (coord.). Cansancio del Leviatán: problemas políticos de la mundialización. 2003, pp. 261-284. . Globalização: teoria social e cultura global. Petrópolis: Vozes, 1999.

ROBINSON, William. "Globalization and the sociology of Immanuel Wallerstein: a critical appraisal”. International Sociology, vol. 26, $\mathrm{n}^{\circ}$ 6, 2011, pp. 723-745.

SASSEN, Saskia. Sociologia da globalização. Porto Alegre: Artmed, 2010. 
SCHMIDT, Volker H. "Modernidade e diversidade: reflexões sobre a controvérsia entre teoria da modernização e a teoria das múltiplas modernidades". Revista Sociedade e Estado, vol. 26, nº 2, 2011, pp. 155-183.

WALLERSTEIN, Immanuel. "Robinson's critical appraisal appraised". International Sociology, vol. 27, $\mathrm{n}^{\mathrm{o}}$ 4, 2012, pp. 524-528.

"The actor and world-systems analysis: comments on Blau and Wieviorka”. Contemporary Sociology, vol. 34, n 1, 2005, pp. 9 -10.

Recebido em: 20/06/2015

Aprovado em: 30/03/2016 